\title{
O FANTASMA TRAVESTI: UMA RAPSÓDIA QUEER
}

\author{
The transvestite ghost (O fantasma travesti): a queer rhapsody
}

\author{
Emerson Silvestre \\ https://orcid.org/0000-0001-6925-2087 \\ Instituto Federal de Pernambuco - campus Recife, Recife, PE, Brasil. 507405-45 - \\ dgcr@recife.ifpe.edu.br
}

\begin{abstract}
Resumo: Este artigo apresenta uma análise crítica do romance $O$ fantasma travesti (1988), de Sylvia Orthof, cuja forma e construção das personagens travam proximidades com o discurso da teoria queer no que se refere à desconstrução dos arquétipos binários de gênero e da performatividade enquanto dispositivo de criação de novas maneiras de se entender o corpo, o gênero e as sexualidades. Tendo como escopo teórico as contribuições de Butler (2015) e Louro (2001), propomos uma aproximação entre a teoria queer e a teoria da ficção com a finalidade de compreender o romance de Orthof enquanto um processo no qual a política da escrita, conceito sugerido por Rancière (1995), desempenha um papel importante na representação da personagem Ziriguidum. Criada sob a égide da paródia de gênero e sob a influência da narrativa fantástica, Ziriguidum é uma ode ao queer. A linguagem com a qual ela se constrói reverbera a ambiguidade e a inconstância que caracterizam a teoria queer, além de ilustrar a confusão pronominal que se instaura quando há a necessidade de se referir às pessoas trans.

Palavras-chave: Ficção. Literatura brasileira. Teoria queer. Transgêneros.
\end{abstract}

\begin{abstract}
This article presents a critical analysis of Sylvia Orthof's novel O fantasma travesti (The transvestite ghost) (1988), whose form and the characters construction closely match the discourse of queer theory regarding the deconstruction of binary gender archetypes and performativity as a creation of new ways of understanding body, gender and sexualities As theoretical scope we bring the contributions of Butler (2015) and Louro (2001) and we propose an approximation between queer theory and fiction theory in order to understand Orthof's novel as a process in which the politics of writing, a concept suggested by Rancière (1995), plays an important role in the representation of the character Ziriguidum. Created under the aegis of gender parody and under the influence of fantastic narrative, Ziriguidum is a ode to queerness. The language with which it is built reverberates the ambiguity and inconstancy that characterize queer theory, besides it illustrates the pronominal confusion that arises when there is a need to refer to trans people.
\end{abstract}

Keywords: Brazilian literature. Fiction. Queer theory. Transgenders.

\section{Introdução}

Publicado na década de oitenta, O fantasma travesti definitivamente é um romance pouco

Esta obra está licenciada sob uma Creative Commons - Atribuição 4.0 
conhecido de uma autora cuja obra é geralmente atrelada ao público infantil. Em tese de doutoramento dedicada à obra de Sylvia Orthof, Marcia Andrade Moral Cabral (2017) afirma que: "A autora se vale do cômico e do ridículo para desmontar, questionar o mundo dos adultos, a autoridade constituída e as instituições [...]" (2017, p. 28). A tese citada tem como corpus de estudo textos que compõem a literatura infanto-juvenil de Orthof, mas as características apontas podem também ser observadas n'O fantasma.

Em resumo, a obra em questão é um texto fantástico no qual o narrador, um recém-morto, conta sua experiência enquanto um fantasma à procura do descanso eterno. Orthof traz para o romance a fantasia do universo infantil por meio de uma linguagem que por vezes beira o pornográfico e o escatológico.

Sarobá, o mundo paralelo onde vivem os espíritos da trama e cenário das mais absurdas ações, é governado por um/uma deus-deusa travesti chamada Ziriguidum. Todas as referências feitas à Ziriguidum surgem na superfície do texto pela inexatidão da colocação pronominal, variando entre os pronomes masculino e feminino e, na maioria das vezes, utilizando ambos simultaneamente. Em Sarobá, o tempo e o espaço são fulgurações facilmente transpassadas pela lógica da fantasia, o narrador ora está em Sarobá, ora na China, ou na Vinte e Cinco de Março comprando adereços para as fantasias de Ziriguidum.

Além disso, elementos como a lua, o sol, as estrelas e alguns animais - especificamente o burro que serve de meio de transporte para Ziriguidum -, são personagens tão reais quanto o narrador que, no seu relato pós-morte, tenta dar conta da imaterialidade fantasmagórica de Sarobá e de seus habitantes. Sobre o espaço, a própria autora nos adverte na introdução pra ninguém ler, sua apresentação ao romance, que se trata de uma versão alucinógena do que ela mesma experienciara quando jovem:

Este livro é fruto da fantasia que se largou. Por isso, peço licença e desboco o português, escrevo torto e nem sei se as linhas estão certas. Eu vivi num lugar parecido com Sarobá, faz tanto tempo! E como eu era muito moça, cercada de gente bem mais velha, danei de imaginar aquele pessoal em ritmo de fantasmas. Sendo no sul da Bahia, eles fizeram uma espécie de bandalheira do além, lá no sem-censura da minha alucinação. Daí, surgiu o livro. (ORTHOF, 1988, p. 5).

Se levarmos em consideração apenas essas três categorias de análise (personagens, espaço e tempo) podemos dizer que, do ponto de vista formal, o romance de Sylvia Orthof (1988) é queer ao apagar qualquer vestígio de lógica narrativa e ao desafiar o Realismo com o qual a produção da década de oitenta costumava tratar a ficção literária. Do ponto de vista temático, ao apostar em uma personagem transgênero como deusa desse universo diegético, o romance levanta discussões importantes no âmbito da representação: qual o local das travestis no contexto histórico dos anos oitenta, a década da epidemia da Aids? A forma como Ziriguidum se apresenta na narrativa, reforça ou renova a maneira como as travestis eram e são comumente lidas pela esfera social (como garotas de programa, violentas, marginalizadas etc.)?

Para sanar esses questionamentos, faz-se necessário compreender o que diz a teoria queer sobre o corpo, o gênero e a sexualidade, e, além disso, é necessário entender também as 
intersecções dos estudos queer com os estudos literários. Dessa maneira, sugerimos uma aproximação entre os campos de estudos por meio de uma categoria cara a ambos: a ficção. Tanto a literatura quanto o gênero e os corpos dissidentes alicerçam suas bases na ficção, na possibilidade de recriar a realidade por meio da linguagem, seja ela estritamente verbal ou através da paródia de gênero sugerida por Butler (2015).

Quando exploramos o potencial (re)criador da ficção literária, percebemos que há também uma dimensão política que subjaz a prática da escrita, o que Rancière (1995) denomina de política da escrita. Essa política diz respeito ao poder de contestação que a ficção literária pode assumir perante a realidade e a verdade instauradas como naturais/normais. Essa postura contestadora trava aproximações também com a teoria queer e seu discurso, por vezes anárquico, acerca das representações de gênero.

Pretende-se, portanto, observar essas características da política da escrita, assim como a dimensão queer que circunscreve tanto a forma como o tema de O fantasma travesti, lendo-o como um processo de imbricados dispositivos narrativos que contribuem para a construção de uma rapsódia literária na qual se observa a construção de uma personagem que redesenha o espectro da representação das travestis na década de oitenta.

\section{Teoria queer e campo literário}

Por definição, podemos dizer que queer é aquilo ou aquele que surge contra a assepsia higienista da heteronormatividade compulsória. Ou: aquilo que se revela estranho, dissidente, transgressor. E ainda: epistemologia "pós-tudo", hoje isso, amanhã aquilo; quer-se o direito de uma pós-identidade, diferente daquela que coloca a homossexualidade em uma caixa translúcida de aceitação à semelhança da heterossexualidade. Sobre essas questões, Louro (2001) escreve que:

Ao alertar para o fato de que uma política de identidade pode se tornar cúmplice do sistema contra o qual ela pretende se insurgir, os teóricos e as teóricas queer sugerem uma teoria e uma política pós-identitárias. $\mathrm{O}$ alvo dessa política e dessa teoria não seriam propriamente as vidas ou os destinos de homens e mulheres homossexuais, mas sim a crítica à oposição heterossexual/homossexual, compreendida como a categoria central que organiza as práticas sociais, o conhecimento e as relações entre os sujeitos. Trata-se, portanto, de uma mudança no foco e nas estratégias de análise; tratase de uma outra perspectiva epistemológica que está voltada, como diz Seidman, para a cultura, para as "estruturas linguísticas ou discursivas" e para seus "contextos institucionais". (LOURO, 2001, p. 541).

Se falamos em uma epistemologia queer, pressupomos que há um modo queer de pensar, anarquista em certa medida, que visa a desestruturar uma política comportamental que se instaura como natural e normal. A "teoria pós-tudo", ou pós-identitária a qual citamos finca seus postulados na perene seara do porvir e na ideia (utópica?) de um desprendimento total do binarismo de gênero que categoriza os corpos em masculino ou feminino.

$\mathrm{O}$ fato é que o queer existe e a insistência da academia em tentar trazer esses assuntos 
para discussão é, de certa maneira, queer. Desafiar a política, que a todo custo tenta invisibilizar as identidades de bordas - para utilizar um termo de Spivak (2010) -, requer alguma coragem nem sempre bem vista.

Queremos dizer, com isso, que há uma política queer. Conceituamos: práticas que minam as políticas do corpo, do sexo e do gênero, extrapolando as barreiras delas para alcançar os discursos de poder que estão atrelados aos usos desse corpo, desse sexo e desse gênero. Em outras palavras, são atos políticos que denunciam a soberania das normalidades machistas, heterossexuais e binárias e suas consequências a nível social. A política queer é o grito de "we're here, we're queer, get used to it" "1 que remonta a rebelião de Stonewall e que ecoa nos atos mais simples como poder usar o banheiro de acordo com o gênero que o indivíduo escolhe para si.

Entender a política através da ótica queer significa abarcar em uma proposta "guardachuva" toda gama de identidades desviantes do eixo heteronormativo, que regula a sociedade. Aprofundando mais a discussão podemos mesmo dizer que a teoria queer traz novas formas e novos conhecimentos para o âmbito político, isto é, lança novas diretrizes sobre a maneira de se fazer política. É por isso que se fala do potencial político da teoria queer, que não se prende apenas aos estudos de identidade de gênero, mas que alcança a sociologia, as artes e a educação, dentre tantas outras áreas do saber.

E no que se refere à literatura, que espaço tem a teoria queer no campo literário? Podemos dizer que a teoria queer funciona como um esquema de representação de discursos minoritários, sobretudo aqueles que se referem ao gênero ou às práticas sexuais dissidentes. Por seu caráter interseccional, acreditamos que a teoria queer tem contribuído com a crítica literária, também, para o protagonismo das escritoras, uma vez que contesta os cânones majoritariamente masculinos, brancos e de classe média. Basta observar o estudo de Regina Dalcastagnè (2012) sobre a preponderância masculina nas publicações brasileiras para termos ideia do quão é importante feminilizar e queerizar o cânone:

Só para citar alguns números, em todos os principais prêmios literários brasileiros (Portugal Telecom, Jabuti, Machado de Assis, São Paulo de Literatura, Passo Fundo Zaffari \& Bourbon), entre os anos de 2006 e 2011, foram premiados 29 autores homens e apenas uma mulher (na categoria estreante, do Prêmio São Paulo de Literatura). Outra pesquisa, mais extensa, coordenada por mim na Universidade de Brasília, mostra que de todos os romances publicados pelas principais editoras brasileiras, em um período de 15 anos (de 1990 a 2004), 120 em 165 autores eram homens, ou seja, 72,7\%. Mais gritante ainda é a homogeneidade racial: $93,9 \%$ dos autores são brancos. Mais de $60 \%$ deles vivem no Rio de Janeiro e em São Paulo. Quase todos estão em profissões que abarcam espaços já privilegiados de produção de discurso: os meios jornalístico e acadêmico (DALCASTAGNÈ, 2012, p. 14).

Vale salientar também que a teoria queer surge como um dos pilares dos estudos de gênero, contestando as leis do patriarcado e da cisheteronormatividade, as quais têm ditado as

\footnotetext{
${ }^{1}$ Estamos aqui, somos queer, acostumem-se! (Livre tradução do autor).
} 
regras que vigiam os corpos femininos, transgêneros e homossexuais.

No campo literário, a teoria queer, à semelhança dos Estudos Culturais, surge como ferramenta de análise literária a qual se baseia na teoria crítica para redefinir a maneira como a sexualidade e o gênero dissidentes são abordados na produção literária. Interessada em estudar obras que se debruçam sobre a representação de tais identidades, a perspectiva queer insere no panorama dos estudos literários não apenas uma forma de se analisar obras, mas, também, de se observar do ponto de vista das minorias, quem escreve esses textos.

Ao deslocar o foco analítico dos textos comumente considerados pela academia como pertencentes ao cânone, a teoria queer lança novos olhares para a crítica literária no tocante a temas como valor estético, representação/autorrepresentação e autoria. Isso significa dizer que há, como foi dito anteriormente, uma inclinação em "queerizar" o cânone, em ampliar o panorama de textos e autores que passam a reivindicar seus espaços na disputa pelo poder da representação, isto é, na disputa de quem pode escrever e de quem pode ser lido.

Dessa maneira, a atuação da teoria queer no campo literário vai muito além da mera seleção de textos ou das análises de personagens representativas de sexualidades e gênero dissidentes, ela atua como uma ferramenta que desestabiliza os alicerces do cânone. Muitas vezes essa atuação é vista como uma ameaça por parte de críticos e estudiosos da literatura que apontam um apagamento de especificidade quando o texto literário é encarado sob a ótica da teoria queer. Sobre o tema, concordamos com os estudos de Eneida Maria de Souza (2002), os quais sugerem que a diluição das fronteiras que separam determinadas áreas do conhecimento é um movimento natural da ciência:

Os estudos contemporâneos situados no campo das ciências humanas colocam-nos diante desse desafio, incitando-nos a não só nos interessarmos pela especificidade disciplinar como a ampliarmos o olhar frente aos cruzamentos e afinidades transdisciplinares (SOUZA, 2002, p. 23-24).

O pretenso apagamento de fronteiras disciplinares em nenhum momento significa a perda de especificidade. Sendo assim, o que Souza sugere é justamente um diálogo em que a literatura possa circular entre esferas diversas de conhecimentos sem que tenha seu aspecto estéticoficcional comprometido. Sendo assim, a teoria queer atua no campo literário também como um dispositivo político, uma vez que a "política da dissidência" é um dos principais alicerces dos estudos queer. Seguindo esse raciocínio, gostaríamos de realizar uma tentativa de aproximação entre a teoria queer e a literatura tendo como foco o eixo político que circunscreve ambas.

\section{Ziriguidum como representação da política queer}

Quando falamos em política, não queremos dizer que $O$ fantasma travesti é planfetário de determinado posicionamento político, queremos dizer, na verdade, que o romance em questão é capaz de desestruturar o discurso político com que comumente as categorias de gênero, sexualidade e corpo são embasadas. Quando uma travesti é escolhida para figurar como deusa de um universo paralelo, no qual ela ocupa o lugar mais importante na narrativa, a força política dessa escolha proporciona uma ruptura na maneira com que o discurso do imaginário 
social tem tratado as travestis no curso da história, sobretudo na década de oitenta, quando o romance foi publicado.

Nesse ponto, a literatura traça fortes laços com os Estudos Culturais ao democratizar a discussão acerca de tais experiências e desestrutura os discursos "oficiais" e "verdadeiros" sobre as identidades trans. O fantasma travesti, não apenas pelo tema que aborda, mas pela maneira como reverbera as vozes até então deixadas à margem do cânone literário, possui uma força contestadora o que o aproxima de uma postura queer, isto é, de um posicionamento que visa à desautomatização das construções sociais que circunscrevem os gêneros, a sexualidade e o corpo, construções estas pautadas no discurso médico-biológico e no discurso religioso que sedimentaram a visão binária e cisheteronormativa.

Para entender essa desautomatização, a teoria queer tem grande valia, pois é através de seus postulados que podemos afirmar o nível ficcional dos corpos. A ideia de performatividade de Butler (2015), que afirma ser o gênero uma construção social e que os corpos desempenham papéis previamente instituídos histórica e socialmente, papéis estes que podem ser moldados com o livre uso do corpo (daí a ideia de performatividade), dialoga diretamente com a leitura desconforme que se faz, por exemplo, de Ziriguidum:

Quando o status construído do gênero é teorizado como radicalmente independente do sexo, o próprio gênero se torna um artifício flutuante, com a consequência de que homem e masculino podem, com igual facilidade, significar tanto um corpo feminino como um masculino, e mulher efeminino, tanto um corpo masculino como um feminino (BUTLER, 2015, p. 26, grifos da autora).

O que Butler (2015) teoriza é justamente o desprendimento do sexo no corpo, isto é, a categoria "sexo", que no curso da história vem ditando o comportamento dos corpos em sociedade, passa a ser questionada enquanto parte indispensável do processo de construção do gênero e, consequentemente, do próprio corpo.

Ziriguidum representa perfeitamente a performatividade dos gêneros sugerida por Butler (2015), uma vez que sua construção, assim como toda a narrativa, flerta com os tons do fantástico e do exagero, fazendo com que a deusa se apresente como uma caricatura não-binária:

Montada num cabrito, toda paramentada de jabuticabas e cajus, surgiu a figura
mais insolitamente chegante. Era como se fosse um símbolo, mas com formato
humano. Tinha seios enormes. Na ponta de cada mamilo, brilhava uma estrela.
No ventre, que se esparramava sobre o vergado animal, havia uma faixa, onde
podia-se ler algo em latim, que talvez fosse "liberdade, mesmo tardia" [...].
Reparei que a fantástica aparição segurava uma navalha, e fazia a barba,
cortando o rosto, de leve, por descuido, ou furando, com impaciência, uma
jabuticaba. No seu rosto havia sinais de grande irritação, e seus olhos, de falsos
cílios, muito maquiados de azul, estavam raivosos [...]. O cabrito dava
chifradas no tronco da árvore e Ziriguidum caiu de ponta cabeça. Por debaixo
de suas saias, as pernas abertas, revelavam a falta absoluta de sexo: nem era
homem, nem mulher. (ORTHOF, 1988, p. 16-17). A constatação de que a deusa não possui órgão sexual desmantela a construção do gênero 
atrelado ao sexo, noção na qual o masculino e o feminino têm fincado suas bases. Não há, para Ziriguidum, referências a seguir na determinação do seu gênero, daí o título de deus-deusa travesti. O termo travesti é usado no romance para designar o exagero: os seios enormes, os cílios e a maquiagem carregada, mas, de fato, a deusa está muito mais próxima de uma idealização queer, isto é, Ziriguidum é a encarnação da dissidência dos gêneros.

Em outras passagens do texto, a deusa é comparada aos comunistas em meio a um interrogatório do DOPS, e também a um deus infernal, pois quando se zanga é possível sentir o cheiro de enxofre. Além disso, ela ainda é cantada como a deusa da Anarquia (como sugere a canção abaixo), Ziriguidum é, na verdade, uma antideusa:

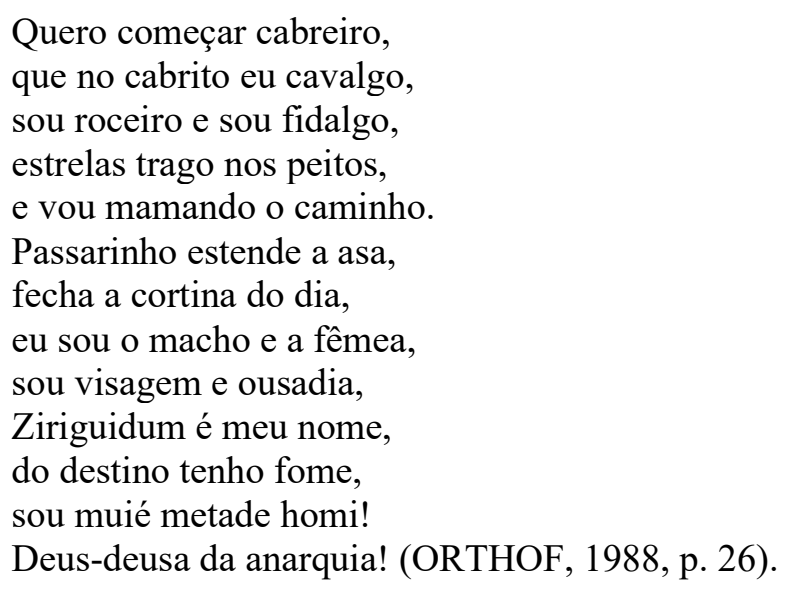

O romance de Orthof antecipa muito das discussões que ainda se travariam sobre o corpo e suas possibilidades, sobre as performances dos gêneros e sobre a fluidez que muitas vezes subscrevem as expressões de gênero. Ziriguidum, como o próprio romance descreve, é um símbolo, e como tal, representa um conceito por inteiro, sem necessidade de explicações. Ziriguidum é a uma bola de demolição a caminho das paredes da cisnormatividade. É daí que surge a força política do romance, por meio da potência dissidente que a deusa travesti sugere e que figura, no romance, através do estatuto ficcional que circunscreve não apenas o fazer literário, mas também a própria construção do gênero de Ziriguidum.

\section{Política queer e política da literatura}

Levando-se em consideração o potencial político dos estudos queer, nosso intuito agora é o de colocá-lo em diálogo com a política da literatura ${ }^{2}$. O texto literário segue uma gramática própria, ou seja, a gramática da política da literatura, a qual não restringe ou classifica fatos linguísticos em nomenclaturas imemoráveis, mas propõe um alargamento do limite do sensível.

Essa perspectiva sugerida por Rancière $(1995 ; 2009)$ parece possibilitar o diálogo entre as políticas queer e a política da literatura quando a aproxima de uma ideia trans(viada ${ }^{3}$. Se a

\footnotetext{
${ }^{2}$ Rancière (1995) fala sobre a política da escrita e sobre o potencial político da arte de maneira geral. Sempre que nos referirmos à política da literatura estaremos fazendo uma aproximação com a política da escrita e com a política da estética também.

${ }^{3}$ Gostaríamos que o termo "trans(viada)" fosse entendido em sua acepção queer, isto é, "trans" referindo-se às identidades transgêneras e "viada" como queer (estranho, bicha, numa tradução livre do inglês).
}

Anu. Lit., Florianópolis, v. 25, n. 1, p. 39-52, 2020. ISSNe 2175-7917 
percepção queer causa mal-estar nas formas instituídas das políticas do corpo, sexo e gênero, de maneira similar, a literatura opera uma política de subversão da realidade instaurada. Portanto, o escritor/poeta é partidário de uma forma peculiar de perceber o mundo. Se a política impõe diretrizes, a literatura as sugere, e ao sugerir, desmantela o discurso político, assim como o faz o olhar queer sobre a heteronormatividade.

Não queremos dizer com isso que todo texto literário possui essa força política, mas concordamos com Rancière (2009) quando o mesmo diz que o simples fato de escrever e de construir realidades possíveis a partir da escrita já é, em si, um ato político por estabelecer outras formas de entender a realidade e de contestar o status de verdade. Podemos inferir, portanto, que a política da escrita se instaura no ato de escritura e não somente na temática do texto.

Essa característica do texto literário - que podemos estender às outras formas de arte constitui o que Rancière (2009) denomina de práticas estéticas, que são:

[...] formas de visibilidade das práticas das artes, do lugar que ocupam, do que "fazem" no que diz respeito ao comum. As práticas artísticas são "maneiras de fazer" que intervêm na distribuição geral das maneiras de fazer e nas suas relações com maneiras de ser e formas de visibilidade. (RANCIÈRE, 2009, p. 17).

Essas outras maneiras de fazer o que comumente se faz ou se toma como "normal" é perceber que há outros níveis de interpretação no que diz respeito às formas de visibilidade. É nesse sentido que a escrita alcança uma dimensão política, ela reorganiza - por meio da desorganização - discursos impostos em nome de uma pretensa normalidade: "A escrita é política porque traça, e significa, uma re-divisão entre as posições dos corpos, sejam eles quais forem [...], porque opera uma re-divisão entre a ordem do discurso e das condições". (RANCIÈRE, 1995, p. 8).

A aproximação feita tem o intuito de demonstrar que o termo queer ultrapassa o sentido restrito de alguma coisa que obrigatoriamente envolva sexualidades destoantes. Queer é isso também, mas quando dizemos que a política da literatura é, por excelência, queer, queremos fazer ver que a força da estética do texto literário em modificar discursos estanques e em dar visibilidade aos discursos à margem a coloca em um patamar tão intenso quanto a política do corpo reivindicado pela teoria queer.

Tendo a linguagem como a instituição da literatura, a política da escrita (da literatura), se possível for exemplificar, funciona da seguinte maneira: o escritor/poeta é o detentor dessa linguagem e, ao produzir o texto, sua tarefa é destituir essa linguagem. A linguagem é destituída de sua aderência à realidade social, isto é, na literatura, a linguagem passa a desempenhar outras funções além daquela de nível informativo. Em outras palavras: o alargamento das possibilidades do real, essa é a política da literatura.

A teoria dos mundos possíveis, que Dolezel (1997) desenvolve, dialoga com a política da escrita de Rancière (1995): ambas firmam suas possibilidades na crítica à razão, na crença em uma razoabilidade da organização do real. Dessa maneira, ao artista cabe a tarefa de renovação 
do mundo através da linguagem. A literatura firma um compromisso contra o desencantamento do mundo. Diferentemente da política em seu sentido restrito (essa dos partidos e das corrupções), a política da literatura é o constante encantamento do mundo, é a consciência de que o combustível vital da arte é o encantamento que decorre da capacidade de recriar o real.

Vale salientar que o vocabulário utilizado (encanto, esperança, vital), aparentemente piegas e pouco preciso, tem que ser entendido em toda a sua potência política, ou seja, se há uma força que nos pressiona e nos sufoca a desacreditar na estética (em algo que nos apresente outras escapatórias à arma apontada para as nossas cabeças, também conhecida pelo nome de "realidade") então esse vocabulário é o exemplo mais concreto de resistência que a literatura pode exercer sobre a realidade.

As intersecções entre política queer e política da literatura estão também na descaracterização da crença absoluta no real (na crítica da razão), na desautomatização das gramáticas sociais e na criação de mundos possíveis. Mas de que maneira ambas alcançam seus objetivos? Penso que a teoria da literatura e a teoria queer exercem suas políticas de diversas maneiras, mas acredito que é através do estatuto da ficção que elas encontram seus dispositivos em prol de suas políticas.

Nesse ponto, escolho, como eixo paradigmático, falar sobre a construção do gênero e de como a literatura atua na perspectiva de desconstruir o binarismo com que comumente este gênero vem sendo analisado. Uma incursão nos principais pontos teóricos acerca da teoria queer parece necessária, entretanto, não intento realizar uma revisão de literatura e muito menos me perder nas armadilhas teóricas que a própria teoria arma para si mesma.

Como já foi dito, a literatura usa a linguagem como ferramenta na construção de seus mundos possíveis. Seguindo o mesmo raciocínio, a teoria queer também tem na linguagem seu principal dispositivo de desconstrução. Judith Butler (2015) credita à linguagem a importância da performatividade dos corpos (e consequentemente dos gêneros), isto é, é por meio da linguagem com que os corpos se revestem (vocabulário, vestuário, gestos) que os gêneros podem ser observados. Essa perspectiva vai de encontro ao que vaticina o discurso médicobiológico, para quem os gêneros se dão em consonância com o órgão genital do indivíduo.

Em determinado ponto da sua teorização labiríntica e confusa em Problemas de gênero, Butler (2015) diz que os corpos ficcionalizam os gêneros, contudo a filósofa não explica como isso acontece. Nesse ponto, acredito que a literatura tem uma explicação para a inexatidão do pensamento de Butler (2015): a teoria da ficção. Claramente o estatuto do ficcional (as teorias acerca da ficção) não se restringem ao campo literário, mas é por meio da teoria da literatura que procuro entender o dispositivo ficcional dos gêneros a partir de uma epistemologia queer.

Ao pensarmos que o texto literário opera a sistemática da construção de mundos possíveis, partindo da realidade social para ultrapassá-la, estabelecemos uma aproximação entre gênero e literatura, pois o gênero também parte da realidade (o masculino e o feminino) para se recriar. A realidade do texto ficcional não surge de um vácuo, ou de um mundo absolutamente estranho, na verdade, ele organiza e apresenta o mundo e o real de outras maneiras, assim criase o efeito de "coisa nova", o que podemos estender à ficcionalidade dos gêneros que, por meio 
de novos modos de apreensão do discurso, pode criar novos meios de se ler os corpos.

O gênero está encriptado no corpo que é transpassado pela linguagem. Esse corpo, por sua vez, só faz sentido quando posto em circulação numa esfera discursiva a qual pressupõe, pelo menos, duas leituras: a dele mesmo e o que se fala dele, isto é, o corpo e como os outros leem esse corpo.

Uma equação semelhante pode ser feita quando nos detemos à questão da literatura: também feita por/na linguagem, o texto literário (re)cria a vida, produzindo novas possibilidades de real, por meio do que Iser (2002) e sua Estética do Efeito denominam de fingimento:

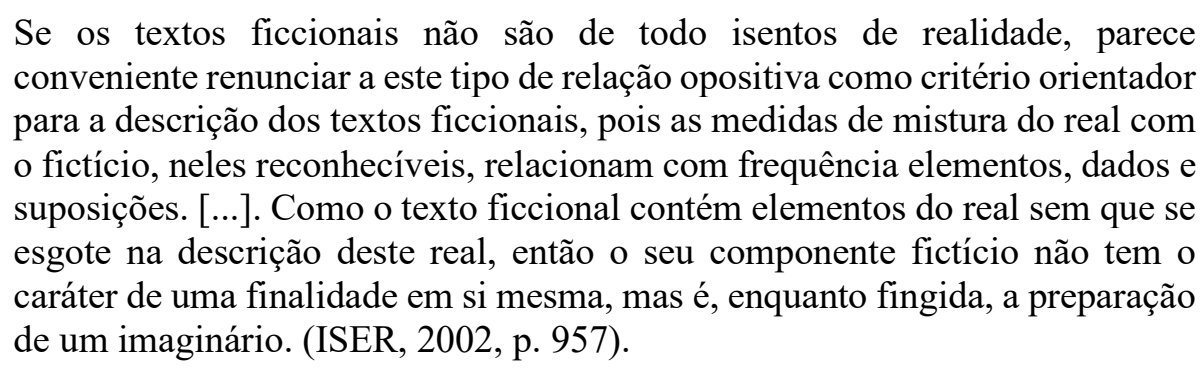

Segundo essa perspectiva, a literatura não é apenas uma linguagem estranha, desviante como queria uma parcela dos formalistas russos - mas é também e, sobretudo, capaz de "desrealizar" o real e moldá-lo num universo diferente (diegese). Essa relação, por sua vez, não se faz por meio da anulação do real concreto, ou da simples representação dele no universo literário, mas sim pela recriação e reapresentação desse real. Isso nos permite dizer que mesmo a ideia estritamente mimética da literatura (defendida por muitos) deve ser compreendida, também, como uma possibilidade criativa, uma vez que seleciona dados da realidade empírica para ressignificá-los.

Portanto, a relação entre gênero e literatura não está apenas no nível superficial de quem escreve o texto literário (se homem, mulher, ou as minorias sexuais), ou das representações femininas e queer nos textos literários (literatura como espelho do mundo), mas tal relação pode ser entendida como dispositivo do próprio fazer literário, e alcançar outros universos (diegético, psicanalítico, social). Observa-se isso quando relacionamos a natureza discursiva do gênero com a natureza ficcional da literatura, ambas calcadas no trabalho transformador da linguagem.

A diferença entre a política da literatura e a política queer talvez resida no fato de que a teoria queer parte de uma atitude por vezes panfletária e atua por meio de uma teorização e metodologia difícil de seguir, seja pela fluidez dos conceitos, ou pela própria atitude de se fazer incompreensível. A literatura alcança o nível de desconstrução (para usar um termo pósestruturalista) sem que seja necessário teorizar sobre o fato. Explico: a literatura, por meio da linguagem (e aqui me refiro ao eixo sintagmático do texto) desestabiliza o real através de recursos narrativos e imagéticos sem que seja necessário justificar. O texto por si só se justifica.

É isso que observamos em O fatasma travesti: a desestabilização do status quo do regime binário de gênero e da heterossexualidade compulsória, tudo isso impresso na personagem Ziriguidum. Construída sob o signo do fantástico, essa personagem flerta, propositalmente, com 
os limites dos gêneros e das sexualidades, agindo como uma entidade, posto que ele/ela é um fantasma-deus, e, como tal, se utiliza dessa ambiguidade para se impor enquanto um ser superior.

A ambiguidade de Ziriguidum, contudo, se sustenta em uma performance que remonta a das travestis, sobretudo aquelas que se apresentam artisticamente em números de transformismo, isso porque a narrativa a descreve, em diferentes passagens do romance, enquanto uma figura montada, em aparições que são verdadeiros acontecimentos artísticos:

Eu fiquei alucinada com umas borboletas de lantejoulas roxas [...]. O balconista tirou a gaveta e colocou sobre o balcão. Ai, Ziriguidum entrou em transe, pois dentro da gaveta, além de borboletas roxas, havia prateadas, douradas, vermelhas, furta-cor, verdes, azuis claras e escuras e umas outras [...]. Não sabíamos o que escolher. Optei pelas negras, depois, achei que, sem dúvida, as prateadas eram as que mais refletiam a luz. Nisso, Ziriguidum comentou, numa entonação de veredicto:

- Você foi travesti em outra encarnação!

- Eu? Mas sou mulher - respondi.

- Quem tem atração por vidrilhos, missangas e lantejoulas, foi bicha, ou travesti, na outra encarnação! É por isso que nós duas nos damos bem! explicou Ziriguidum, que tinha descoberto um vidro de purpurina prateada e jogou sobre minha cabeça.

- Sabe o que é isso/ - perguntou Ziriguidum. E antes que eu pudesse responder, deu uma requebrada e explicou:

- Purpurina! É caspa de travesti! (ORTHOF, 1988, p. 63-64)

Apesar do clichê e do estereótipo da travesti enquanto uma figura espalhafatosa, a construção dessa personagem nos revela uma mudança no eixo com o qual as travestis costumam ser representadas na literatura, uma vez que sua existência não está condicionada ao abandono, à violência física ou à prostituição, pelo contrário, Ziriguidum é uma deusa e, enquanto tal, possui a capacidade da onipresença e da onisciência, o que impõe certo respeito dentro do universo diegético do romance.

A rapsódia construída entorno de Ziriguidum a coloca como a heroína do romance, como a deusa de um mundo paralelo que, apesar de parecer distante, está em permanente contato com o "mundo real". Ziriguidum passeia entre os dois mundos montada em seu burro mágico que viaja livremente pelas múltiplas possibilidades do espaço-tempo. O romance de Orthof (1988), desse ponto de vista, encerra uma novidade até então impensável no que se refere à representação das travestis na literatura brasileira, sobretudo na década de oitenta, na qual a Aids era um vírus gay e a população LGBT seu principal vetor.

\section{Conclusão}

No final do romance, quem assume a narrativa é Monique, uma travesti morta, que escreve do além e, à semelhança de Ziriguidum, possui o dom da onipresença. O recurso narrativo utilizado por Sylvia Orthof (1988) cria o efeito de mise en abyme onde coexistem diferentes focos e tempos narrativos nos quais se misturam as personagens e apaga-se a narração originária, isto é, em $O$ fantasma travesti importa muito mais o que e como se conta do que 
quem conta.

$\mathrm{O}$ artigo que determina o gênero no título do romance contradiz a maneira como Ziriguidum e a própria narradora se identificam enquanto expressão e identidade de gênero. Isso se dá, provavelmente pela época de publicação do romance - na década de oitenta as pessoas trans e travestis eram tratadas como homossexuais - e pela falta de representatividade que a comunidade transgênero possuía. Não raramente, observam-se no texto a utilização exacerbada da concordância de gênero no masculino para se referir às travestis, mas, apesar disso, e levando-se em consideração o já mencionado contexto histórico da obra, o romance de Orthof (1988) encerra leitura surpreendente não apenas pela escolha da temática e das personagens (principalmente pela construção de Ziriguidum), mas também pela ousadia no que se refere à forma do romance.

O fantasma travestis é uma verdadeira rapsódia narrativa na qual coexistem gêneros literários diversos (canção, poema) escrito em uma linguagem que tenta imprimir a velocidade com que as ações acontecem. Apesar de se tratar de um romance fortemente influenciado pelo universo maravilhoso das histórias infantis (seara literária pela qual Sylvia Orthof é conhecida), percebe-se um forte tom de denúncia na construção das personagens e também no seu desfecho, quando Monique relata que está morta, assim como suas outras amigas travestis, representando a triste realidade das pessoas transgêneros: "Foi há muito tempo. Hoje, ainda não sei contar. Calo os detalhes. São dolorosos demais. Urrei, implorei. Ninguém escuta um travesti, ninguém escuta" (ORTHOF, 1988, p. 169).

A dimensão queer do romance de Sylvia Orthof não reside apenas no título, ou na representação por vezes estereotipada das travestis, incorporada por Ziriguidum. Essa dimensão alcança o nível da construção do próprio texto e atenua a força política da escrita enquanto dispositivo que questiona o binarismo de gênero e a violência que circunscreve a experiência trans. Apesar de ser um romance pouco conhecido e de estar fora dos compêndios da literatura brasileira, O fantasma travesti impressiona pela originalidade e pela maneira como tenta desvirtuar a gramática normativa que regula as identidades e expressões de gênero, lê-lo sob a égide da teoria queer é a forma que encontramos de "queerizar" o cânone.

\section{Referências}

BUTLER Judith. Problemas de gênero: feminismo e subversão da identidade. Trad. de Renato Aguiar. Rio de janeiro: Civilização Brasileira, 2015.

CABRAL, Marcia Andrade Morais. Semiótica e argumentação: análise das obras de literatura infantil de Silvia Orthof. Tese (Doutorado em Letras Vernáculas) - Faculdade de Letras da Universidade Federal do Rio de Janeiro, Programa de Pós-graduação em Letras Vernáculas, Universidade Federal do Rio de Janeiro, Rio de Janeiro, 2017.

DALCASTAGNÈ, Regina. Literatura brasileira contemporânea: um território contestado. Vinhedo: Editora Horizonte, 2012.

DOLEŽEL, Lubomír et al. Teorías de la ficción literária. Compilação de textos, introdução e bibliografia de Antonio Garrido Domínguez. Madrid: Arco/Libros S.L.,1997. 
ISER, Wolfgang. Os atos de fingir ou o que é fictício no texto ficcional. In: LIMA, Luiz Costa (Org.). Teoria da Literatura em suas fontes. Rio de Janeiro: Civilização Brasileira, 2002. v. 2. p. 955-985.

LOURO, Guacira Lopes. Teoria Queer: Uma política pós-identitária para a educação. Revista Estudos Feministas, Florianópolis, v. 9, n. 2, p. 541-553, 2001.

ORTHOF, Sylvia. O fantasma travesti. Rio de Janeiro: Espaço e Tempo, 1988.

RANCIÈRE, Jacques. Políticas da escrita. Rio de Janeiro: Ed. 34, 1995.

RANCIÈRE, Jacques. Partilha do sensível: estética e política. Trad. de Mônica Costa Netto. São Paulo: EXO experimental org; Editora 24, 2009.

SOUZA, Eneida Maria de. Crítica Cult. Belo Horizonte: Editora UFMG, 2002.

SPIVAK, Gayatri Chakravorty. Pode o subalterno falar? Trad. de Sandra Regina Goulart Almeida, Marcos Pereira Feitosa, André Pereira Feitosa. Belo Horizonte: Editora UFMG, 2010.

\section{NOTAS DE AUTORIA}

Emerson Silvestre (emesilvestre@gmail.com) é doutorando em Letras (teoria da literatura) pela Universidade Federal de Pernambuco e mestre em Letras pela mesma instituição. Possui bacharelado em Letras também pela UFPE e licenciatura em Letras português/inglês pela Faculdade São Miguel. Atua nas áreas de Teoria da Literatura, Crítica Literária, Estudos Culturais e Ensino de Língua Estrangeira. Atualmente é professor do Instituto Federal de Pernambuco (IFPE), campus Recife.

Como citar esse artigo de acordo com as normas da revista

SILVESTRE, Emerson. O fantasma travesti: uma rapsódia queer. Anuário de Literatura, Florianópolis, v. 25, n. 1, p. 39-52, 2020.

\section{Contribuição de autoria}

Não se aplica.

Financiamento

Não se aplica.

\section{Consentimento de uso de imagem}

Não se aplica.

\section{Aprovação de comitê de ética em pesquisa}

Não se aplica.

\section{Licença de uso}

Este artigo está licenciado sob a Licença Creative Commons CC-BY. Com essa licença você pode compartilhar, adaptar, criar para qualquer fim, desde que atribua a autoria da obra.

\section{Histórico}

Recebido em: 16/01/2020 
Revisões requeridas em: 29/02/2020

Aprovado em: 23/03/2020 